\title{
Two-dimensional quasi-static debonding in GFRP/balsa sandwich panels
}

\author{
Aida Cameselle-Molares, Anastasios P. Vassilopoulos, Thomas Keller* \\ Composite Construction Laboratory (CCLab), École Polytechnique Fédérale de Lausanne \\ (EPFL), Station 16, Bâtiment BP, CH-1015 Lausanne, Switzerland
}

\begin{abstract}
The two-dimensional (2D) debonding behavior of GFRP/balsa sandwich panels presenting embedded circular disbonds at the face sheet/core interface was experimentally investigated. The bottom of the panels was fixed and out-of-plane quasi-static tensile loads were applied to open the crack. Two different face sheet configurations were studied. The first consisted of a pure woven ply layup while in the second, layers of continuous filament mat (CFM) were placed above and below the woven plies. The inclusion of CFM layers at the face sheet/core interface resulted in an enhanced fracture behavior exhibiting improved load-bearing performance and significant crack arrest. In-plane stretching strains appeared in the deformed face sheets due to the $2 \mathrm{D}$ embedded nature of the crack. The magnitude of the stretching was quantified based on the in-plane strains monitored throughout the experiments. As a result of the stretching, shear mode contributions were activated, causing the initiation of secondary cracks in the pure woven configuration and crack migration in the woven/CFM configuration. The migration in the latter occurred from the face sheet/core interface to the woven/CFM interface, generating dense fiberbridging. This intensified fiber-bridging was found to be the main cause of the alreadymentioned improvement in the fracture performance of the woven/CFM configuration.
\end{abstract}

Keywords: 2D crack propagation; quasi-static; fracture; debonding; sandwich panels.

\section{Introduction}

Sandwich structures are currently used in a wide number of engineering applications where lightweight and efficient structural systems are required. Notably, systems formed by fiberreinforced polymer (FRP) face sheets and low-density cores have been extensively and traditionally employed in the naval, aerospace or automotive industries. Thanks to the important advantages provided by FRP sandwich structures, such as high strength- and stiffness-to-weight ratios, rapid installation and versatility, the number of FRP sandwich structural elements used in civil infrastructure applications has increased [1-3]. Specifically, GFRP sandwich bridge

\footnotetext{
${ }^{*}$ Corresponding author. Tel: +41216933226; e-mail: thomas.keller@epfl.ch
} 
decks offer great thickness flexibility, which constitutes a significant advantage for conceiving longer spans [4-5]. Honeycomb, foam (with shear GFRP webs) and balsa cores are usually employed in sandwich deck designs. Balsa cores are particularly advantageous due to their sufficient shear capacity and uniform support for the upper face sheet in contact with the frequent wheel loads [4-6].

When disbonds between the face sheets and the core occur either during manufacturing or due to impacts during the structural life service, the bearing capacity and thus the structural integrity of a sandwich member may be affected [7-8]. Mode I-dominated debonding is considered the most critical phenomenon in sandwich structures [8-9]. The existence of embedded disbonds in structural elements under pure compression or bending may induce premature face sheet wrinkling [10], causing the disbonds to open and thus to propagate under out-of-plane tensile stresses. Likewise, geometrical changes in the sandwich structure (e.g. changes of depth or curvatures), resulting in deviations of the action line of the face sheets' in-plane stresses, may lead to significant out-of-plane tensile stresses and thus to Mode I-dominated debonding scenarios.

To improve the face/core adhesion, layers of reinforcement with randomly oriented fibers such as chopped strand mat (CSM) or continuous filament mat (CFM) have been typically used in sandwich applications [11]. By adding these layers in the interface between the face sheet and core, a gradual stiffness transition zone is provided and the resin flow during fabrication of the panels is increased, thus avoiding dry areas. Furthermore, this type of layer is prone to develop fiber-bridging, providing additional fracture toughening of the interface and therefore improving the damage tolerance. The effect on the debonding fracture behavior of the layup at the face sheet/core interface of GFRP/foam sandwich panels, under different degrees of modemixity, was investigated in [12]. One of the examined face sheet's layups consisted of four layers of quadriaxial $(90,45,0,-45)$ reinforcement, a layer of woven reinforcement and a layer of CFM. The latter was in contact with the core. Mode I-dominated loading caused the crack to propagate in the resin between the core and face sheet, while in Mode II-dominated loadings the crack migrated into the CFM layer causing the increase in fiber-bridging and fracture resistance. The crack never penetrated the woven layer. Additionally, for strongly Mode IIdominated cases, secondary cracks initiated between the woven layer and the quadriaxial plies. 
Due to the critical importance of Mode I-dominated debonding in the structural performance of FRP sandwich elements, numerous test methods to evaluate and characterize the face sheet/core opening fracture behavior have been extensively discussed in the literature [7, 13-20]. Owing to the inherent elastic property mismatch at the interface between the core and the face sheets, crack propagation always occurs under a certain degree of mode-mixity [21]. Thus, of all the investigated specimen configurations, the single cantilever beam (SCB) method has been found to be the most appropriate as a compromise between experimental simplicity and Mode Idominated loading conditions $[8,9,22,23]$. Double cantilever beam specimens loaded by uneven moments (DCB-UBM) was also proved to be a suitable test method to characterize any mode-mixity, ranging from Mode I-dominated to Mode II-dominated, but it does however require a much more complex set-up [12].

All these experimental methods rely on beam-like one-dimensional (1D) specimens where the crack debonds with an approximately constant crack width in the longitudinal direction of the specimens. Nevertheless, debonding damage in actual structural members may span all around the perimeter, constantly modifying the size of the crack front.

An experimental investigation of the fracture delamination behavior of GFRP plates with embedded circular pre-cracks (i.e. 2D delamination) and subjected to out-of-plane opening loads was carried out in [24]. Results proved that, due to the boundary conditions inherent to an embedded crack growing in a laminated plate, a stiffening of the plates due to the appearance of in-plane stretching stresses occurred. Plates with a fiber architecture composed of layers of CFM were further numerically investigated in [25]. Results confirmed a 50\% increase, compared to standard 1D DCB specimens with the same layup, in the required strain energy release rate (SERR). The increase of the developed fiber-bridging, as a result of the increase in the flexural stiffness (1D beams vs $2 \mathrm{D}$ plates) together with the previously mentioned stress stiffening effect, was found to cause this SERR increase.

Currently, 1D debonding fracture properties are typically used in the numerical modeling of 2D debonding scenarios [26-28]. Nevertheless, 2D effects similar to those addressed in 2D delamination are expected to occur when fiber-bridging develops as a result of a $2 \mathrm{D}$ crack debonding in sandwich panels, therefore limiting the validity of 1D standard fracture results. 
The main objective of this work was therefore to investigate the experimental 2D debonding in GFRP/balsa sandwich panels, thus extending the 2D fracture investigation initiated for $2 \mathrm{D}$ delamination in laminated plates in [24]. For this purpose, a new experimental set-up was developed. Circular embedded disbonds were introduced in the center of the face sheet/core interface and quasi-static out-of-plane tensile loads were applied to open the crack. In order to achieve a Mode-I-dominated loading and thus minimize the shear mode fracture contributions due to the elastic mismatch, the bottom of the sandwich panels was fixed, as in the set-up of the SCB. A total of four panels and two different face-sheet configurations were investigated: a pure woven layup and a combination of woven plies and CFM layers. The latter were placed at the face sheet/core interface to evaluate their effect on the debonding fracture performance. In view of the results from [24], a stretching of the face sheets and consequent shear mode contributions were expected. To quantify the magnitude of the stretching, in-plane strains were monitored throughout the experiments. Post-mortem cuts of the panels were made through the thickness to evaluate the crack propagation paths. Additionally, the influence of the fracture process zone (FPZ) on the experimentally obtained in-plane strain profiles and the evolution of the inflection points throughout the experiments were also discussed.

\section{Experimental program}

\subsection{Material description}

The face sheets of the investigated sandwich panels were fabricated with two types of glass fiber reinforcements: a $390-\mathrm{g} / \mathrm{m}^{2}$ weight woven fabric (W) with a proportion of 50/50 in the warp/weft directions (provided by Swiss-Composite, Switzerland) and a long continuous filament mat (CFM) of $600-\mathrm{g} / \mathrm{m}^{2}$ weight (provided by Owens Corning, United States). The fracture behavior of both types of reinforcement under Mode I-dominated conditions was individually investigated at the laminate level in [24]. Photos of the two reinforcements are shown in Fig. 1. An epoxy resin (Sicomin SR8100) suitable for infusion techniques was selected. The properties of the glass fibers and resin can be found in Table 1 (manufacturer data [29-31]). Commercial BALTEK ${ }^{\circledR}$ VCB balsa wood was used for the core (supplied by Colevo, Switzerland). An average density of $228.40 \mathrm{~kg} / \mathrm{m}^{3}$ was determined for the provided pieces.

\subsection{Specimen description and fabrication}

The experimental program consisted of two pairs of GFRP/balsa sandwich panels with two different configurations of the GFRP face sheet (i.e. a total of four panels). The first configuration consisted of 18 plies of woven reinforcement (designated SPA) while for the 
second (SPB) a symmetric layup combining nine woven plies with two plies of CFM above and another two plies below was selected. The description of each panel type can be found in Table 2. The SPB layup was selected in order to obtain an axial and flexural stiffness comparable to those of the SPA configuration. The values were determined using Classic Laminate Theory (CLT). The lamina properties of each of the reinforcements used were estimated following the formulation presented in [24]. The values corresponding to each type of face sheet are given in Table 2 and, as can be observed, there is only a $13 \%$ and $17 \%$ difference in bending and axial stiffness respectively. Furthermore, a symmetrical layup was also selected to avoid any bending-extension coupling effect. The dimensions of the balsa core (see Table 2) were the same for all panels.

The layout of the sandwich panels is presented in Fig. 2. As can be observed, a pre-crack between the GFRP face sheet and the balsa core of $60-\mathrm{mm}$ diameter was created at the center of each panel. The opening load to propagate the pre-crack was transferred from the machine to the panels by means of a 30-mm head and 10-mm shank screw (see Fig. 2). The perimeters of the surface of the head of the screw in contact with the face sheets were smoothened to remove sharp edges. Furthermore, the face sheets were anchored to the lateral sides of the balsa core to guarantee that no other cracks initiated distant from the pre-crack. The fabrication and assembling process followed to achieve the final design is described in the following.

First, in order to permit the subsequent insertion of the loading screw, a hole of 30-mm diameter was drilled in the center of the balsa core (see Fig. 2(b) and Fig. 3 (Step 1)). The vacuum infusion technique was employed to produce all the sandwich panels and therefore the abovementioned hole in the balsa core was duly sealed before the infusion by a polyoxymethylene (POM) cylinder and mastic (see Fig. 3, Step 2). A Teflon film of 13- $\mu$ m thickness was placed at the center of the balsa core (i.e. over the sealed hole) to introduce the pre-crack and the layers of reinforcement were placed over it. To reinforce the top of the loading region (i.e. the center of the panels), three additional circular woven reinforcement layers of 60 -mm diameter were added for both the investigated configurations. All the panels were infused with a centered resin inlet and two lateral resin outlets, as can be seen in Fig. 3, Step 3. Following the infusion process, the panels were cured under vacuum for 12 hours at room temperature and subsequently eight hours at $45^{\circ} \mathrm{C}$. Finally, after demolding the panels, the sealing POM cylinder was removed, a hole of $10-\mathrm{mm}$ diameter was drilled at the center of the face sheets and the screw was inserted (Fig. 2(b)). 
To connect the bottom of the panels to the machine, a system of two steel plates was designed. One of the plates (designated S1, see Fig. 2) was glued with an epoxy adhesive (Sikadur 330) to the bottom surface of each panel. The adhesive was applied inside a $200-\mathrm{mm}$ width, $200-\mathrm{mm}$ height and 2-mm depth volume carved on the top surface of S1 in order that, after placing the panels on top, an adhesive layer of 2-mm thickness was assured (see Fig. 2 and Fig. 3, Step 4). Moreover, each S1 steel plate had an additional cylindrical steel element with the same diameter as that of the hole drilled in the balsa (i.e. $30 \mathrm{~mm}$ ) to avoid any leaking of adhesive inside the hole. Thus a total adhesive surface of $39293 \mathrm{~mm}^{2}$ was obtained. The correct alignment of all the elements in the vertical axis of the load was guaranteed by a guiding system consisting of two small cylindrical elements fixed on S1 and coincident with holes of the same dimensions at the bottom of the panels, as indicated in Fig. 3, Step 4. The second steel plate, designated S2, consisted of two joined sub-elements: a horizontal element fixed by eight screws to S1 and a vertical element onto which the bottom grip was finally tightened (see Fig. 2).

\subsection{Experimental set-up and instrumentation}

All the experiments were performed under displacement control at a rate of $1.5 \mathrm{~mm} / \mathrm{min}$. The tensile load was applied by a $\mathrm{W}+\mathrm{B}$ electromechanical machine of $50-\mathrm{kN}$ capacity at a temperature of $24 \pm 2^{\circ} \mathrm{C}$ and relative humidity of $38 \pm 5 \%$. The experimental set-up is shown in Fig. 4. The panels were first fixed and completely constrained by the bottom grip of the machine assuring, with the help of a level, that they were horizontal. The loading screw was then tightened to the surface of the panels by means of a nut, a washer and a rubber ring in order to evenly distribute the pressure (see Fig. 2). Lastly, the panels were fixed to the top grip using an in-house developed hinge so that any small rotation of the screw due to crack propagation would not damage the loading cell of the machine.

The load and displacement during crack propagation were obtained from the machine (accuracy $\pm 0.11 \%$ ). In order to subtract from the total measured displacement the contribution due to the deformation of the core and bottom fixation and thus obtain the opening displacement, the panels were equipped with four Linear Variable Differential Transducers (LVDTs, accuracy of $\pm 0.02 \mathrm{~mm}$ ). To install them precisely at the level of the interface between the face sheet and core, four windows were opened in the middle of each of the four lateral sides of the panels (see Fig. 4). 
Three measuring systems were used to monitor the 2D propagation of the crack: a digital camera, 3D Digital Image Correlation (DIC) and visual measurements, as presented in Fig. 5. For each panel, six rulers starting from the end of the pre-crack and with markers every $2.5 \mathrm{~mm}$ were drawn on three quarters of the panel top surface (see Fig. 5). The crack propagation along four of these rulers was monitored by a digital camera placed above the panels (see location in Fig. 4) used to take pictures of the area at an acquisition frequency of $0.2 \mathrm{~Hz}$. The corresponding load and displacement values were recorded for each picture and the value of the crack front was determined by visually post-processing the images. The propagation along the remaining rulers was monitored in-situ by visual inspection. Thanks to the translucency of the face sheet laminates, the crack front was identified by the whitening of the delaminated areas. The 3D DIC system (accuracy $\pm 0.005 \mathrm{~mm}$ ) was used in one quarter of the surface (see Fig. 5) where a random speckle pattern was applied using white paint and black spray paint. The location of the 3D DIC cameras is shown in Fig. 4. The acquisition frequency of the images was also 0.2 Hz. The change from straight to curved out-of-plane deformation profiles of the face sheet derived from the DIC was assumed as the crack front. The post-processing of the results was carried out using Vic-3D software from Correlated Solutions Inc. [32]). The DIC system was also used to extract the in-plane strain distributions in the measuring region with an accuracy of $\pm 0.01 \%$.

\section{Experimental results}

\subsection{Load and crack-opening displacement responses}

The load and crack-opening displacement responses measured for the SPA and SPB configurations are shown in Fig. 6. Since the cracks propagated concentrically throughout all the experiments, as can be observed for the SPA.1 panel in Fig. 5, the values of the crack front in Fig. 6 are given in terms of total radial crack length (i.e. with the 30-mm radius of pre-crack included). As can be observed, increasing curves after crack initiation were obtained for both configurations, as was also the case for the laminates investigated in [24]. Initially, before the initiation of the crack, similar stiffnesses were exhibited by the two configurations, confirming that the selected layups had comparable bending stiffness, as described in Section 2.2. After crack initiation, and during the first millimeters of crack propagation, no obvious variation of stiffness was observed. It then progressively decreased to a fairly constant stiffness (e.g. after $2 \mathrm{~mm}$ of opening displacement in SPA.2 panel) thus exhibiting a linear increase of the load. Such behavior (also exhibited in the laminated plates in $[24,25]$ ) could be observed for all the panels. 
As the crack propagated and the load and displacement increased, the additional woven circular layers of $60-\mathrm{mm}$ diameter used to reinforce the loading region (see Section 2.2) started detaching, see Fig. 7 (photo at 105-mm total radial crack length). However, due to the local effect they exerted, the detaching did not affect the global stiffness of any of the panels. Subsequently, towards the maximum load, local damage also started to develop in the laminate above the pre-crack, which finally prevented the load from increasing further. The load and displacement values at the maximum load are presented in Table 3 for each panel. The SPB panels achieved higher loads than the SPA panels. After the maximum loads were reached, the cracks stopped propagating. The last values of total radial crack lengths shown in Fig. 6 correspond to the last crack fronts.

\subsection{Compliance behavior}

The compliance of each panel was calculated as $\delta / P, \delta$ being the opening displacement and $P$ the load. In order to assign to each compliance value the corresponding crack area, a cubic fitting of the experimental total radial crack length for each configuration was carried out. The crack area vs compliance results are presented in Fig. 8. Values are given from crack initiation up to a crack area value of $14000 \mathrm{~mm}^{2}$ (i.e. $66.75 \mathrm{~mm}$ of total radial crack length). Although the curves would continue until the last value of propagation, a smaller horizontal segment was selected to better represent the initial behavior of the compliance. An initial decreasing trend was exhibited indicating a stiffening of the panels even after crack initiation. Then a minimum was reached and an increasing trend of the compliance was measured until the end of the experiment, consequently indicating a softening of the panels. This behavior was observed for all the panels. A local effect causing an increase of the compliance before the described decrease was recorded for panel SPA.1. The minima of the compliance are indicated with rectangular markers in Fig. 8. Averaging the total crack area values of each pair of panels at the minimum compliances, values of $3927.6 \mathrm{~mm}^{2}$ (i.e. a total radial crack length of $35.4 \mathrm{~mm}$ ) and 4134.3 $\mathrm{mm}^{2}$ (i.e. a total radial crack length of $36.3 \mathrm{~mm}$ ) were obtained for the SPA and SPB configurations respectively. The load and displacement values corresponding to the minimum compliances of all the panels are presented in Table 3 and shown in Fig. 6.

\subsection{Crack propagation behavior}

Post-mortem inspections of the cracks were carried out by cutting the panels through the thickness to provide direct access to the crack interface. In Fig. 9 side images of the propagated 
cracks are shown for one panel of each configuration and drawings representing the observations are also included for better comprehension. Two different types of cracks were observed in both types of configuration that will hereafter be referred to as primary crack and secondary crack. The primary crack corresponded to the propagation of the pre-crack that was introduced into the interface between the face sheet and balsa core. The secondary crack was a new crack created during the experiments.

As can be observed, in the SPA panels the primary crack propagated throughout the whole experiment in the face sheet/core interface, without any migration. The secondary crack initiated in parallel to the primary crack between the first and second woven plies. Furthermore, the ultimate front of the primary crack corresponded to a shorter propagated radial crack length (referred to as " $b$ " in Fig. 9(a)) than the length corresponding to the ultimate crack front observed during the experiments (see Fig. 6). A value of $b=26 \mathrm{~mm}$ was observed for SPA.1 (i.e. at a total radial crack length of $56 \mathrm{~mm}$ ) while a higher value of $b=58 \mathrm{~mm}$ (i.e. at a total radial crack length of $88 \mathrm{~mm}$ ) was observed for SPA.2. Therefore, the ultimate crack fronts observed from the top of the panels during the experiments corresponded to the front of the secondary crack. The point where the secondary crack overtook the primary crack could not be determined from the post-mortem inspection.

A different behavior of the primary crack was observed for the SPB panels (Fig. 9(b)) in which shortly after crack initiation it already started to penetrate progressively into the CFM layer, thus generating dense fiber-bridging. After approximately $30 \mathrm{~mm}$ of radial propagation (i.e. a total radial crack length of $60 \mathrm{~mm}$ ), the primary crack had completely migrated from the face sheet/core interface into the interface between the CFM and the first woven ply; the woven layer was not penetrated however. The secondary crack, also located between the CFM and the woven layers, either merged with the migrated primary crack or propagated backwards after migration of the primary crack - both scenarios are plausible.

\subsection{Radial and circumferential strain distribution}

The in-plane strains in the top surface of the face sheet were extracted from the 3D DIC measurements. In Fig. 10, the radial and circumferential strain profiles corresponding to a radial path (starting from the end of the pre-crack) in the SPA.2 panel are presented. Two profiles are highlighted: an "early profile" (in green) corresponding to a total radial crack length of 37.5 $\mathrm{mm}$ and a "late profile" (in orange) corresponding to a total radial crack length of $87.5 \mathrm{~mm}$. 
The crack tips are also indicated for each of the highlighted profiles, permitting a clear distinction between the cracked and un-cracked regions. Observing the radial profiles in the cracked region, two types of profile can be distinguished depending on the size of the crack: a full compression strain profile for small cracks and strain profiles partially in compression and partially in tension for longer cracks. The circumferential strains in the cracked region remained in tension throughout the experiments. A typical compression state $[33,34]$ of the laminate in the un-cracked region could be observed throughout the experiment in both strain profiles. The magnitudes of these compression strains were greater in the radial than in the circumferential direction.

\section{Discussion}

\subsection{Load and crack-opening displacement responses}

Throughout the propagation of a 2D embedded crack, the length of the crack front (i.e. the perimeter of the crack) increased, contrasting with the typical 1D behavior of beam-like fracture mechanics experiments where the crack front length remains constant. Specifically, in the cases presented here, equal increments in the radial crack length led to increasing lengths of the concentric crack fronts. The resulting disproportional growth of the crack area forced the load to increase in order to maintain the crack propagation - again in contrast to 1D propagation where the load decreases - as can be observed for all the investigated panels in Fig. 6. Further discussion regarding this $2 \mathrm{D}$ effect can be found in $[28,29]$.

Although all panels presented comparable bending stiffnesses, the SPB panels attained higher loads than the SPA panels (see Fig. 6). For instance, comparing the linear part (after the progressive change of the stiffness) of the load-displacement curves of SPA.1 and SPB.1 panels, a load increase of $\sim 3 \mathrm{kN}$ (i.e. a $\sim 27 \%$ increase) was registered. This enhancement originated as a result of the greater amount of fiber-bridging developed in the SPB panels where, as described in Section 3.3, the crack penetrated the CFM layers thus generating dense fiber-bridging. Additionally, as the crack never penetrated into the woven layers once migrated, the loadbearing part of the laminate (i.e. the woven layers) remained intact throughout the experiments. The effect of crack migration and the consequent dense fiber-bridging was also confirmed by the crack length vs displacement curves (see Fig. 6), where an evident crack arrest in the SPB panels could be observed. Compared to the SPA panels, the total radial crack length was initially reduced by $\sim 20 \%$ and $\sim 26 \%$ for the last propagated crack front in the SPB experiments. It can thus be concluded that the inclusion of CFM layers between the face sheet and core 
considerably improved the $2 \mathrm{D}$ debonding behavior of the sandwich panels under the investigated loading.

The slight difference observed in the load-displacement curves of the SPA panels may be attributed to the crack propagation behavior detailed in Section 3.3 and not to experimental scatter. As described, even though similar propagation paths were exhibited by both panels, the total radial crack length of the primary crack was shorter in SPA.1 than in SPA.2. Assuming that propagation in the resin of the face sheet/core interface (primary crack) required less energy than propagation between two woven plies (secondary crack), the longer the primary crack remained dominant (i.e. in SPA.2), the less energy (and consequently less load) was required. This is in agreement with the experimental results (Fig. 6).

The concentric propagation of the crack in both configurations was directly related to the outer boundary conditions. The edges of the laminates in [24] were free and therefore the crack propagated differently depending on the stiffness of the direction of propagation (e.g. slower in the directions where the fibers were oriented at $\pm 45^{\circ}$ ). However, the edges of the face sheet were completely fixed in this case, leading to a similar propagation all around the contour of the pre-crack.

\subsection{Compliance behavior}

The initially increasing and then decreasing trends in the experimental compliances of the 2D debonding experiments (shown in Fig. 8) were in agreement with the results obtained for 2D delamination in the laminates [24]. Due to the similar 2D nature of the embedded cracks investigated in the laminates and in the studied sandwich panels, the same stiffness-related mechanisms affecting the exhibited compliance were developed: stretching (radial and circumferential) due to the geometrical constraints, fiber-bridging and crack propagation (see [24]). The first two mechanisms decreased the compliance (i.e. stiffened the system) while the propagation of the crack tended to increase the compliance (i.e. soften the system). Before the minimum point, hereafter designated "transition point" (TP) as in $[24,25]$, the stiffening mechanisms prevailed over the softening mechanism, while beyond the TP the crack propagation mechanism became dominant.

The stiffening mechanisms in the laminates developed widely before the propagation of the crack (and thus the softening) became dominant, exhibiting considerable descending branches 
in the compliances down to the TP [24]. However, the TP for all the sandwich panels was reached almost immediately after crack initiation, exhibiting only a short branch of decreasing behavior in the compliance (Fig. 8) and indicating an initial rapid crack growth and barely developed stiffening mechanisms. This earlier occurrence of the TP was caused by the smaller pre-crack area used in the sandwich panels $\left(2827.4 \mathrm{~mm}^{2}\right.$ vs $21598.5 \mathrm{~mm}^{2}$ in laminates $)$ and by the higher stiffness of the investigated face sheets compared to any of the laminated plates in [24], causing the cracks to initiate at low levels of opening displacement (see Table 3) with consequently barely deformed (and thus barely stretched) face sheets. Furthermore, the crack growth trend also differed. The laminated plates exhibited initially slow crack growth rates that progressively increased throughout the experiments [24]. Fast initial crack growth rates following a progressive decrease were however obtained for the sandwich panels (see Fig. 6).

The TP in the laminates was particularly characteristic as it was found to correspond to the full development of the fiber-bridging area (see [25]) and the linearization of the load-displacement curves. However, the early appearance of the TP prior to any relevant development of the stiffening mechanisms meant that these conclusions were no longer valid for the investigated sandwich panels. Additionally, the described multi-crack scenarios for both panel configurations and the crack migration for the SPB panels (see Section 3.3) prevented any correlation to a single fiber-bridging area propagation in a single interface. Regarding the linearization of the load, although it could not be related to the TP (also shown in Fig. 6), it still occurred, as for the laminated plates, i.e. equilibrium between the stiffening and softening mechanisms was present.

\subsection{Analysis of strain profiles}

According to the experimental set-up, the center of the crack (i.e. the loading area) and the crack front could both be assumed as being fully constrained, with only free vertical movement at the loading area. Consequently, as the crack opened and the face sheet deformed, an inflection point appeared in the radial profile to allow the radial change of curvature, different at both ends. Theoretically, this inflection point would move away from the loading region as the crack propagated. Furthermore, under pure bending conditions, any change from a tension to compression strain state, such as those exhibited in Fig. 10(a) in the radial strain profiles (i.e. zero strain points between the crack tip and pre-crack), would necessarily imply a change in the curvature of the deformed face sheet and therefore correspond to an inflection point. However, evaluating the out-of-plane deflections of the face sheet (also extracted from DIC 
measurements), no apparent inflection point existed at zero strain points (on the top surface). This could be attributed to the existence of the in-plane radial tensile strains (as a result of the radial stretching), which counteracted the compression strains in the compressed top surface (i.e. the one monitored with the DIC) and increased the tensile strains in the already tensioned bottom surface and thus shifted the zero strain point from its pure bending position. For the described boundary conditions, the circumferential curvature stayed constant and therefore only tensile strains appeared in the top surface of the face sheet (Fig. 10(b)). Consequently, the corresponding circumferential tensile stretching strains were contributing to simply increase the tensile strains in the top surface.

\subsubsection{Derivation of in-plane radial stretching strains}

An example of the radial out-of-plane deflection profile obtained from the top surface of the SPA.2 panel at a total radial crack length of $88 \mathrm{~mm}$ is shown in Fig. 11(a). The corresponding radial strain profile (top surface of the face sheet) measured with the DIC is presented in Fig. 11(b). As previously mentioned, no inflection point was visually apparent in the out-of-plane deflection profile at the zero radial strain point (i.e. at a total radial length of $40.85 \mathrm{~mm}$ ) due to the superimposed stretching (tensile) strains. In order to determine the latter ( $\varepsilon_{s}$ in Fig. 11(b)), the following procedure was applied. First, a third order polynomial equation was fitted to the out-of-plane deflection profile so that a continuous description of the curvature (i.e. the second derivative of the deflection) was obtained. Then, using the values of the curvature, the thickness of the face sheet and strain profile at the top of the face sheet $(\varepsilon t)$, the strain profile on the bottom surface $(\varepsilon b)$ was calculated. Lastly, using the top and bottom strain values, the stretching strains were calculated. By subtracting the stretching strains from the total top and bottom total strains, the "pure" bending strain profiles were also obtained (see Fig. 11(b)), representing the linear behavior inherent to a punctual load. For the sake of simplicity, a constant face sheet thickness of $5 \mathrm{~mm}$ was used during the calculation without any further consideration regarding the secondary crack propagation interface.

\subsubsection{Influence of the FPZ}

The developed fracture process zone (FPZ), generated mainly due to fiber-bridging, influenced the radial strain profiles immediately behind the crack tip. Theoretically, if the FPZ and the stretching did not exist, the strain profile on the top surface should start from a minimum value (i.e. a maximum compression) at the crack tip, decrease until the inflection point and increase up to a maximum value (i.e. maximum tensile strain) at the loading point. A qualitative sketch 
showing this theoretical pure bending profile between the inflection point and the crack tip is presented in Fig. 12 for both top and bottom surfaces (positive/negative signs indicate tensile/compressive strains). In the event of an FPZ zone with fiber-bridging developing in front of the crack tip, bridging tractions opposing the opening of the crack appear (see bridging traction profiles in Fig. 12). Consequently, the original profile of pure bending (black profile) would be altered, reducing the tensile strains in the bottom surface and the compression in the top surface (green profile). Such an effect has been already reported elsewhere [33, 34]. However, when additional stretching strains appear, two scenarios regarding the strain behavior may apply. In the bottom surface, if the magnitude of the stretching strains is greater than the magnitude of the opposing strains from bridging traction, a continuously decreasing tensile strain profile at the FPZ would be obtained, i.e. the scenario shown in Fig. 12 (orange profile). If the magnitude is smaller however, an initially increasing and then decreasing profile (as if only bridging tractions were acting) would be obtained. In both scenarios, in the top strain profile, where the region of the FPZ is in compression, a greater decrease would occur due to the stretching strains. As a result, the stretching values calculated from the measured top strains may not be accurate close to the FPZ, as the fiber-bridging effect is included and therefore the stretching values may be overestimated.

\subsubsection{Radial stretching strain evolution}

Based on the procedure described in Section 4.3.1, the radial stretching strain profiles for two further total radial crack lengths $(80$ and $105 \mathrm{~mm}$ ) of the SPA.2 panel were derived and are presented, together with the profile at $88 \mathrm{~mm}$, in Fig. 13. For the sake of comparison, the stretching strain values at $60 \%$ of the total radial crack length are indicated for each profile, guaranteeing a sufficient distance from the FPZ and thus avoiding any possible overestimation (see Section 4.3.2). As expected, an increasing trend of the stretching strains (both generally and particularly for the evaluated points) occurred as the crack propagated and the face sheet deformed.

Three stretching strain profiles at 65, 70 and $75-\mathrm{mm}$ total crack lengths for SPB.2 panels are likewise shown in Fig. 14. Considering that in the SPB panels the crack migration generated dense fiber-bridging and that particularly for the SPB.2 panel the crack had fully migrated after $60 \mathrm{~mm}$ of total radial crack length (see Section 3.3), any profile derived for shorter lengths would be highly affected by the generated fiber-bridging. Thus, as mentioned, profiles from 65 $\mathrm{mm}$ onwards were selected, leaving a short margin of total radial crack length to evaluate, as 
the last propagated crack front corresponded to a total radial length of $77.5 \mathrm{~mm}$ (Fig. 6). The indicated strain values corresponded to $70 \%$ of the total crack length for each profile (values at $60 \%$, as selected in Fig. 13, would be affected by the damaging of the loading area). The increasing trend of the stretching strain profiles between the pre-crack and the FPZ with increasing crack length could again be observed. As the loading area was approached, the initial part of the 70 and $75-\mathrm{mm}$ profiles exhibited a slightly decreasing value due to the damage in this area (see also Section 3.1). The stretching strains were again calculated using the total thickness of the face sheet (i.e. $6 \mathrm{~mm}$, see Table 2) without considering the (small) progressive reduction of the section due to migration of the crack.

The dense fiber-bridging developed in the SPB panels led to an increase of the load and crack arrest (compared to the SPA panels). Therefore, for similar crack lengths in both configurations, higher loads and opening displacements were exhibited in the SPB panels (see Fig. 6). This was also reflected in the measured in-plane strains and is particularly evidenced in the higher stretching strains in SPB (Fig. 14) compared to SPA (Fig. 13).

\subsubsection{Inflection point location}

By applying the procedure described in Section 4.3.1 to the measured radial strains, even if the inflection points were located in the pre-crack area (i.e. outside the measuring area), they could always be found by extending the calculated linear pure bending profiles until they intersect (i.e. until zero strain), as shown in Fig. 11(b). In the event of the inflection points being located in the measuring area, they could already be identified in the out-of-plane profile and the derived pure bending linear profiles would already intersect. In order to verify that at the inflection point only stretching stresses existed, the profiles of the total radial strains (top and bottom) and the stretching strain profile were also extended following the shown trend. The convergence point of the three profiles effectively matched the inflection point obtained from the pure bending profiles, thus confirming that only constant through-thickness tensile stresses existed.

The shift of the inflection point's location (with respect to the total radial crack length, i.e. $L / a$ ) for panels SPA.2 and SPB.2 is shown in Fig. 15. As a result of the propagation of the crack, the inflection point would move to the right (i.e. to the exterior of the face sheets). Considering however that, due to the damage caused to the loading region the corresponding boundary conditions evolved from an initial ideal full constraint of the rotations to their progressive partial 
release, the inflection point would move to the left (i.e. to the center of the face sheets). The effective location of the inflection point was thus the result of both opposing effects. For all the panels, the values of $L / a$ at the investigated total radial crack lengths showed an increasing trend, revealing that despite the damage in the loading area, the general shift of the inflection point towards the exterior of the face sheet, as a result of the propagation of the crack, prevailed.

\subsection{Stretching-induced shear fracture modes}

In the 2D delamination cases studied in [24], the crack propagated in the midplane. Therefore, as the crack opened, the upper and lower laminates of the cracked part of the plates deformed similarly thus developing the same stretching strains. As a result, no shear displacement, and thus no shear fracture mode contribution, occurred at the crack tip. However, in the 2D debonding of the sandwich panels, the stretching only developed in the face sheet and the core did not deform, thereby activating stretching-induced shear fracture modes. As mentioned in Section 1, the experimental set-up in the present investigation was developed (based on the SCB specimen) to minimize the shear mode fracture contributions resulting from the elastic property mismatch. Thus, the stretching strains developed in the face sheets were the main source of relevant shear fracture modes. As a result, the crack propagated under mixed-mode conditions (i.e. Mode I/shear modes). The greater the stretching strains, the greater the shear mode contribution.

The crack propagation paths observed in the post-mortem cuts (see Section 3.3) were a reflection of the effect of the stretching-induced shear modes on the crack propagation behavior. In the SPA panels, the shear modes caused the nucleation of a secondary crack, while in the SPB panels they led to the migration of the primary crack from the woven/CFM interface to the woven/CFM interface. Similar crack propagation behavior was found in [12] for 1D DCBUBM specimens presenting a layup similar to the SPB configuration (at the face sheet/core interface level) and strong Mode II loading. Details are given in Section 1.

As reported in [25], there are two different 2D effects (not present in 1D cases) contributing to increase fiber-bridging developed under Mode I: 1) the increase in the flexural stiffness (from beam to plate) and 2) the stress stiffening of the deformed laminate due to the in-plane stretching. Both effects are consequences of the 2D nature of the crack and they thus apply in both delamination and debonding scenarios. In the 2D debonding cases investigated, the migration of the crack and nucleation of new crack surfaces, caused by the shear modes induced 
by the in-plane stretching of the face sheets, led to the development of additional fiber-bridging as the cracks opened. Specifically, the secondary crack in the SPA panels started and propagated in a woven/woven interface that, compared to a woven/core interface, naturally involved more fiber-bridging. Regarding the SPB panels, the migration of the crack through the two plies of CFM and subsequent propagation at the woven/CFM interface triggered high-density fiberbridging. Taking into account the fact that the cracks kept propagating under Mode I, all the new fiber-bridging generated was also enhanced by the two previously mentioned and already known 2D effects. Thus, the stretching-induced mode-mixity can be considered as an additional $2 \mathrm{D}$ effect on cracks propagating under opening loads.

\section{Conclusions}

The 2D debonding in GFRP/balsa sandwich panels with embedded cracks subjected to quasistatic out-of-plane opening loads was experimentally studied. A total of four panels and two different face sheet configurations were investigated. The first configuration (SPA) consisted of a pure woven fabric (W) layup while in the second (SPB) continuous filament mat (CFM) layers were inserted above and below the woven plies. Circular pre-cracks were introduced in the interface between the balsa core and the face sheet. The load-bearing and compliance responses, crack propagation behavior and in-plane strain distributions of the face sheet were analyzed. The influence of the FPZ on the strain profiles and evolution of the inflection points throughout the experiments were likewise discussed. The following conclusions may be drawn from this work:

1. An experimental design appropriate for the investigation of the debonding behavior of 2D embedded cracks under out-of-plane loads in sandwich panels was developed. The design is able to capture the relevant $2 \mathrm{D}$ effects not occurring in $1 \mathrm{D}$ fracture experiments.

2. The introduction of plies prone to the development of fiber-bridging at the face sheet/core interface (i.e. CFM) resulted in an enhanced fracture resistance of SPB panels. An improved load-bearing performance (load increase of approx. 27\%) and significant crack arrest (the propagation of the crack was reduced by 20 to $26 \%$ ) were observed for the SPB compared to the SPA panels. 
3. Due to the 2D nature of the investigated embedded cracks and the corresponding boundary conditions, in-plane tensile stretching strains appeared in the deformed face sheets as the cracks propagated. The magnitude of the radial stretching strains showed an increasing trend with increasing crack propagation in both the studied configurations. Due to the dense fiber-bridging and consequent crack arrest, the SPB panels required higher loads and opening displacements to propagate the crack than the SPA panels. As a result, higher stretching strains also developed in SPB panels (e.g. for an approx. 80 $\mathrm{mm}$ total radial crack length, stretching strains of 0.01 and $0.28 \%$ developed in SPA and SPB panels respectively).

4. Due to the in-plane stretching strains, shear fracture mode contributions were activated throughout the experiments. As a result, the crack in the SPB panels migrated from the face sheet/core interface to the woven/CFM interface and a secondary crack initiated in the SPA panels between the first and second woven plies.

5. The stretching-induced mode-mixity constitutes an additional $2 \mathrm{D}$ effect in cracks propagating under opening loads. Depending on the layup, this can trigger different crack propagation behaviors (e.g. crack migration or nucleation of new crack surfaces). The other two (already known) 2D effects (i.e. increase in flexural stiffness and stress stiffening also caused by stretching) lead to an increase in the developing fiber-bridging. Thus, the additional fiber-bridging activated as a result of the stretching-induced modemixity (third 2D effect) is also increased by the two other 2D effects.

6. These three 2D effects on fiber-bridging do not occur in 1D Mode I-dominated fracture experiments. Their further quantification and separation, i.e. the investigation of the individual contributions, require further FE analysis, which constitutes the next step of this work.

\section{Acknowledgments}

The authors wish to acknowledge the support and funding of this research by the Swiss National Science Foundation (Grant No. 200021_156647).

\section{Data availability statement}


The data required to reproduce these findings cannot be shared at this time as the data also forms part of an ongoing study.

\section{References}

1. Keller, T. Recent all-composite and hybrid fiber-reinforced polymer bridges and buildings. Prog. Struct. Eng. Mater., 2001; 3(2): 132-140.

2. Manalo, A., Aravinthan, T., Fam, A., Benmokrane, B. State-of-the-Art Review on FRP Sandwich Systems for Lightweight Civil Infrastructure. J. Compos. Constr., 2017; 21(1): 04016068-1.

3. Uddin, N. Developments in Fiber-Reinforced Polymer (FRP) Composites for Civil Engineering. $1^{\text {st }}$ ed. Woodhead Publishing; 2013.

4. Keller, T., Rothe, J., De Castro, J., Osei-Antwi, M. GFRP-Balsa Sandwich Bridge Deck: Concept, Design, and Experimental Validation. J. Compos. Constr., 2013; 18(2): 04013043.

5. Osei-Antwi, M., De Castro, J., Vassilopoulos, A.P., Keller, T. Structural limits of FRPbalsa sandwich decks in bridge construction. Composites: Part B, 2014; 63: 77-84.

6. Osei-Antwi, M., De Castro, J., Vassilopoulos, A.P., Keller, T. FRP-Balsa Composite Sandwich Bridge Deck with Complex Core Assembly. J. Compos. Constr., 2013; 17(6): 04013011.

7. Cantwell, W.J., Davies, P. A test technique for assessing core-skin adhesion in composite sandwich structures. Journal of Material Science Letters, 1994; 13: 203-205.

8. Ratcliffe, J.G, Reeder, J.R. Sizing a single cantilever beam specimen for characterizing facesheet-core peel debonding in sandwich structure. Journal of Composite Materials, 2011; 45(25): 2669-2684.

9. Saseendran, V., Berggreen, C., Krueger, R. Mode mixity analysis of face/core debonds in a single cantilever beam sandwich specimen. J. Sandwich Structures and Materials, 2018; $0(0): 1-31$.

10. Rani, E., Grant P., Ashforth C. Composite structures : effects of defects. $1^{\text {st }}$ ed. Hoboken, NJ: John Wiley \& Sons; 2018. 
11. Carlsson, L.A., Kardomateas, G.A. Structural and Failure Mechanics of Sandwich Composites. Solid Mechanics and its Applications, 121. Springer; 2011.

12. Lundsgaard-Larsen, C., Berggreen, C., Carlsson, L.A. Tailoring sandwich face/core interfaces for improved damage tolerance - Part II: experiments. Appl. Compos. Mater., 2010; 17: 621-637.

13. Prasad, S., Carlsson, L.A. Debonding and crack kinking in foam core sandwich beams-II: experimental investigation. Eng Fract Mechs, 1994; 47(6): 825-841.

14. Cantwell, W.J., Scudamore, R. Ratcliffe, J., Davies, P. Interfacial fracture in sandwich laminates. Comp. Sci. Tech., 1999; 54(14): 2079-2085.

15. Li, X., Carlsson, L.A. The tilted sandwich debond (TSD) specimen for face/core interface fracture characterization. J. Sandwich Structures and Materials, 1999; 1: 60-75.

16. Li, X., Carlsson, L.A. Elastic foundation analysis of tilted sandwich debond (TSD) specimen. J. Sandwich Structures and Materials, 2000; 2: 3-32.

17. Ratcliffe, J., Cantwell, W.J. A new test geometry for characterizing skin-core adhesion in thin-skinned sandwich structures. Journal of Material Science Letters, 2000; 19: 13651367.

18. Ural, A., Zehnder, A.T., Ingraffea, A.R. Fracture mechanics approach to facesheet delamination in honeycomb: measurement of energy release rate of adhesive bond. Eng Fract Mechs, 2003; 70: 93-103.

19. Shivakumar, K.N., Smith, S.A. in situ fracture toughness testing of core materials in sandwich panels. Journal of Composite Materials, 2004; 39(8): 655-668.

20. Berggreen, C., Simonsen, B.C., Borum, K.K. Experimental and numerical study of interface crack propagation in foam-cored sandwich beams. Journal of Composite Materials, 2007; 41(4): 493-520.

21. Hutchinson, J.W., Suo, Z. Mixed mode cracking in layered materials. Adv. Appl. Mech., 1991; 29: 63-191.

22. Farmand-Ashtiani, E., Cugnoni, J., Botsis, J. Monitoring and characterization of the interfacial fracture in sandwich composites with embedded multiplexed optical sensors. Composite Structures, 2013; 96: 476-483.

23. Yoshida, K., Aoki, T. Beam on elastic foundation analysis of sandwich SCB specimen for debond fracture characterization. Composite Structures, 2018; 195: 83-92.

24. Cameselle-Molares A., Vassilopoulos A.P., Keller T. Experimental investigation of twodimensional delamination in GFRP laminates. Eng. Frac. Mechs., 2018; 203: 152-171. 
25. Cameselle-Molares A., Vassilopoulos A.P., Renart J., Turon A., Keller T. Numerical simulation of two-dimensional in-plane crack propagation in FRP laminates. Comp. Struc. 2018; 200: 396-407.

26. Chen, Z.M., Krueger, R., Rinker, M. Facesheet/Core Disbond Growth in Honeycomb Sandwich Panels Subjected to Ground-Air-Ground Pressurization and In-Plane Loading. In: 11th International Conference on Sandwich Structures ICSS-11, Ft. Lauderdale, USA, March, 2016.

27. Rinker, M., Krueger, R., Ratcliffe, J. Analysis of an Aircraft Honeycomb Sandwich Panel with Circular Face Sheet/Core Disbond Subjected to Ground-Air Pressurization. NASA/CR-2013-217974, 2013.

28. Moslemian, R., Quispitupa, A., Berggreen C., Hayman, B. Failure of uniformly compression loaded debond damaged sandwich panels - An experimental and numerical study. J. Sandwich Structures and Materials, 2012; 14(3): 297-324.

29. Swiss Composite Product Catalogue. $\quad$ https://www.swisscomposite.ch/pdf/Produkteuebersicht.pdf $>$ (Accessed 16 October 2017).

30. Owen's Corning Reinforcements Composite Solutions Guide. $<$ http://www.ocvreinforcements.com/pdf/library/Composite_Solutions_Guide_100360_E _finalprintable.pdf $>$ (Accessed 26 March 2018).

31. Sicomin SR8100 resin datasheet. <http://www.sicomin.com/datasheets/productpdf94.pdf> (Accessed 12 November 2018).

32. Correlated Solutions Inc. VIC 3D-v7 reference manual. Columbia, USA: Correlated Solutions.

33. Manshadi, B.D., Vassilopoulos, A.P, Botsis, J. A combined experimental/numerical study of the scaling effect on mode I delamination of GFRP. Compo. Sci. Tech., 2013; 83: 3239.

34. Pappas, G., Botsis, J. Intralaminar fracture of unidirectional carbon/epoxy composite: experimental results and numerical analysis. Int. J. Solids and Struc., 2016; 85-86: 114124. 
Tables:

Table 1. Material properties

\begin{tabular}{lcccc}
\hline Material & $\begin{array}{c}\mathrm{E} \\
(\mathrm{GPa})\end{array}$ & $\begin{array}{c}\mathrm{G} \\
(\mathrm{GPa})\end{array}$ & $\begin{array}{c}v \\
(-)\end{array}$ & $\begin{array}{c}\rho \\
\left(\mathrm{g} / \mathrm{cm}^{3}\right)\end{array}$ \\
\hline Epoxy resin & 3.00 & 1.30 & 0.35 & 1.14 \\
E-CR $^{*}$ glass (for CFM) & 80.00 & 32.80 & 0.22 & 2.62 \\
E-glass (for woven) & 72.00 & 29.50 & 0.22 & 2.55 \\
\hline
\end{tabular}

${ }^{*}$ CR: Corrosion-Resistant

Table 2. Description of GFRP/balsa sandwich panels

\begin{tabular}{lccccc}
\hline \multirow{2}{*}{$\begin{array}{l}\text { Panel } \\
\text { type }\end{array}$} & Layout & $\begin{array}{c}\text { Thickness, } \mathrm{t} \\
(\mathrm{mm})\end{array}$ & $\begin{array}{c}\text { Axial } \\
\text { stiffness } \\
(\mathrm{GPa})\end{array}$ & $\begin{array}{c}\text { Bending } \\
\text { stiffness } \\
(\mathrm{GPa})\end{array}$ & $\begin{array}{c}\text { Dimensions of } \\
\text { Baltek }^{\circledR} \text { VBC } \\
\text { balsa core }(\mathrm{mm})\end{array}$ \\
\cline { 2 - 5 } & $(\mathrm{W})_{18}$ & 5 & 128.10 & 266.87 & $400 \times 400 \times 108$ \\
\hline SPA.1/2 & $(\mathrm{CFM})_{2} /(\mathrm{W}) 9 /(\mathrm{CFM})_{2}$ & 6 & 106.01 & 230.90 & $400 \times 400 \times 108$ \\
\hline
\end{tabular}

Table 3. Load-displacement values at initiation, maximum loads and minimum compliances

\begin{tabular}{ccc|cc|cc}
\hline \multirow{2}{*}{ Panel } & \multicolumn{2}{c|}{ At initiation } & \multicolumn{2}{c|}{ At max. load } & \multicolumn{2}{c}{ At min. compliance (TP) } \\
\cline { 2 - 7 } & Disp. (mm) & Load (kN) & Disp. (mm) & Load (kN) & Disp. (mm) & Load (kN) \\
\hline SPA.1 & 0.79 & 4.05 & 13.90 & 16.56 & 1.34 & 6.61 \\
SPA.2 & 0.74 & 3.54 & 10.89 & 14.21 & 1.21 & 6.47 \\
\hline SPB.1 & 0.77 & 3.84 & 7.07 & 15.28 & 1.56 & 8.58 \\
SPB.2 & 0.62 & 2.96 & 8.23 & 16.41 & 1.50 & 8.06 \\
\hline
\end{tabular}




\section{Figures:}

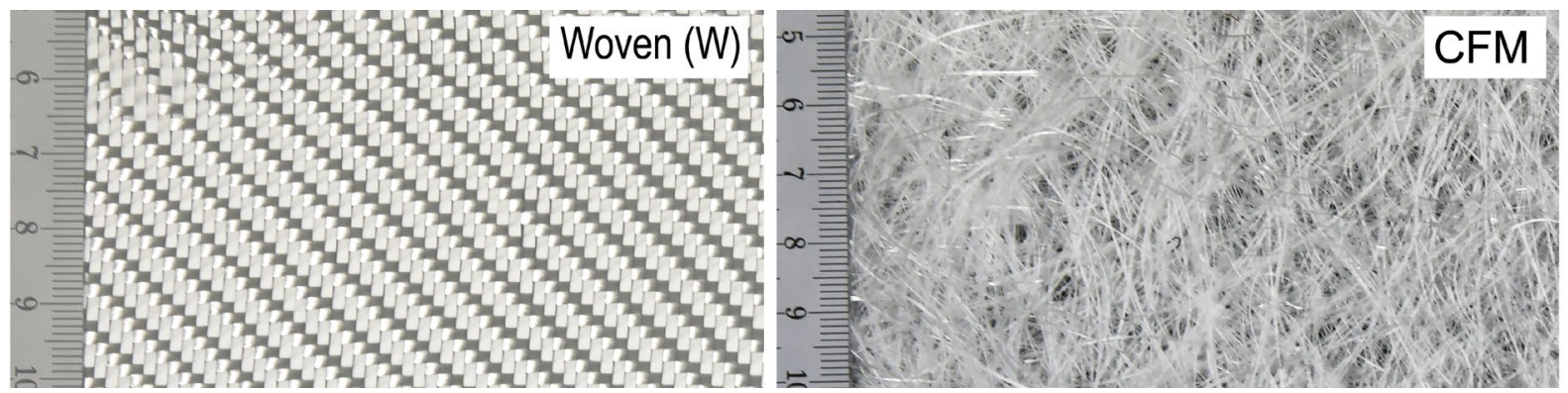

Fig. 1. Detail of glass fiber reinforcements used

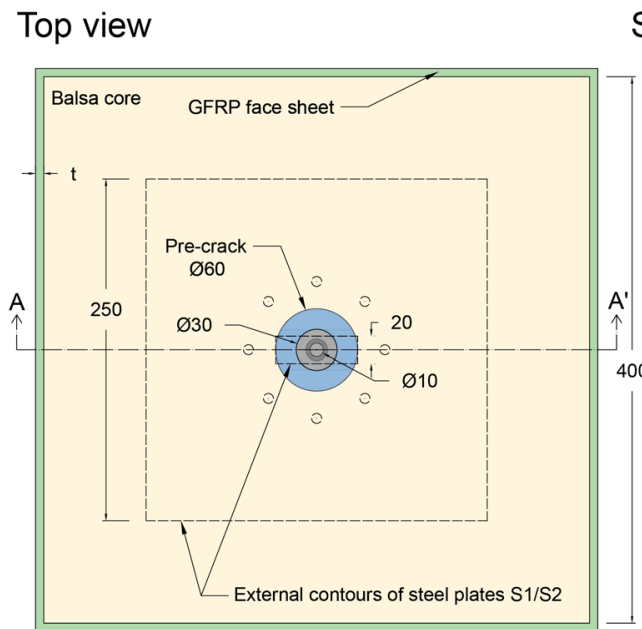

(a)
Side view AA'

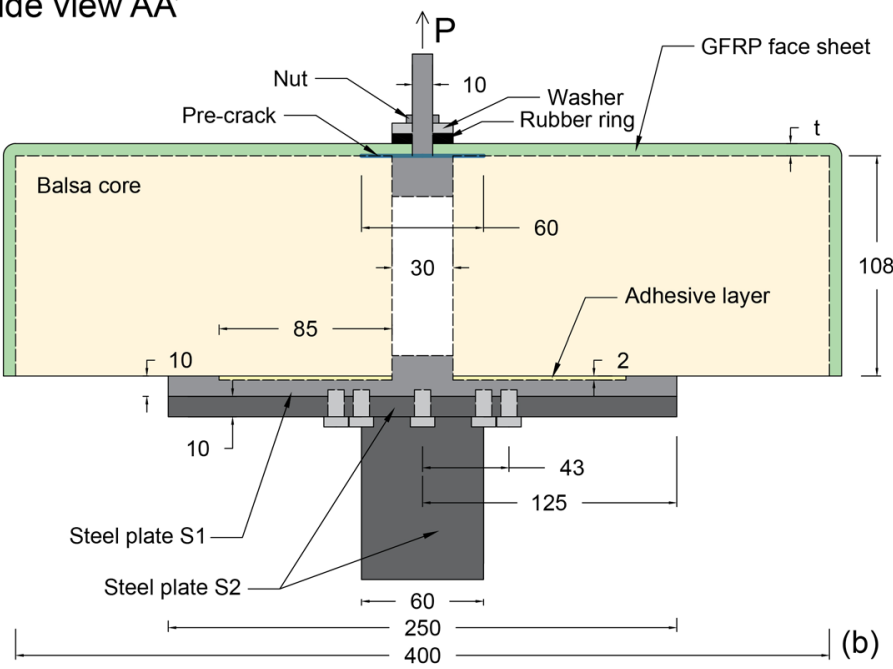

Fig. 2. Sandwich panel layout; (a) Top view and (b) Side view of section AA' in (a).

Dimensions in $\mathrm{mm}$

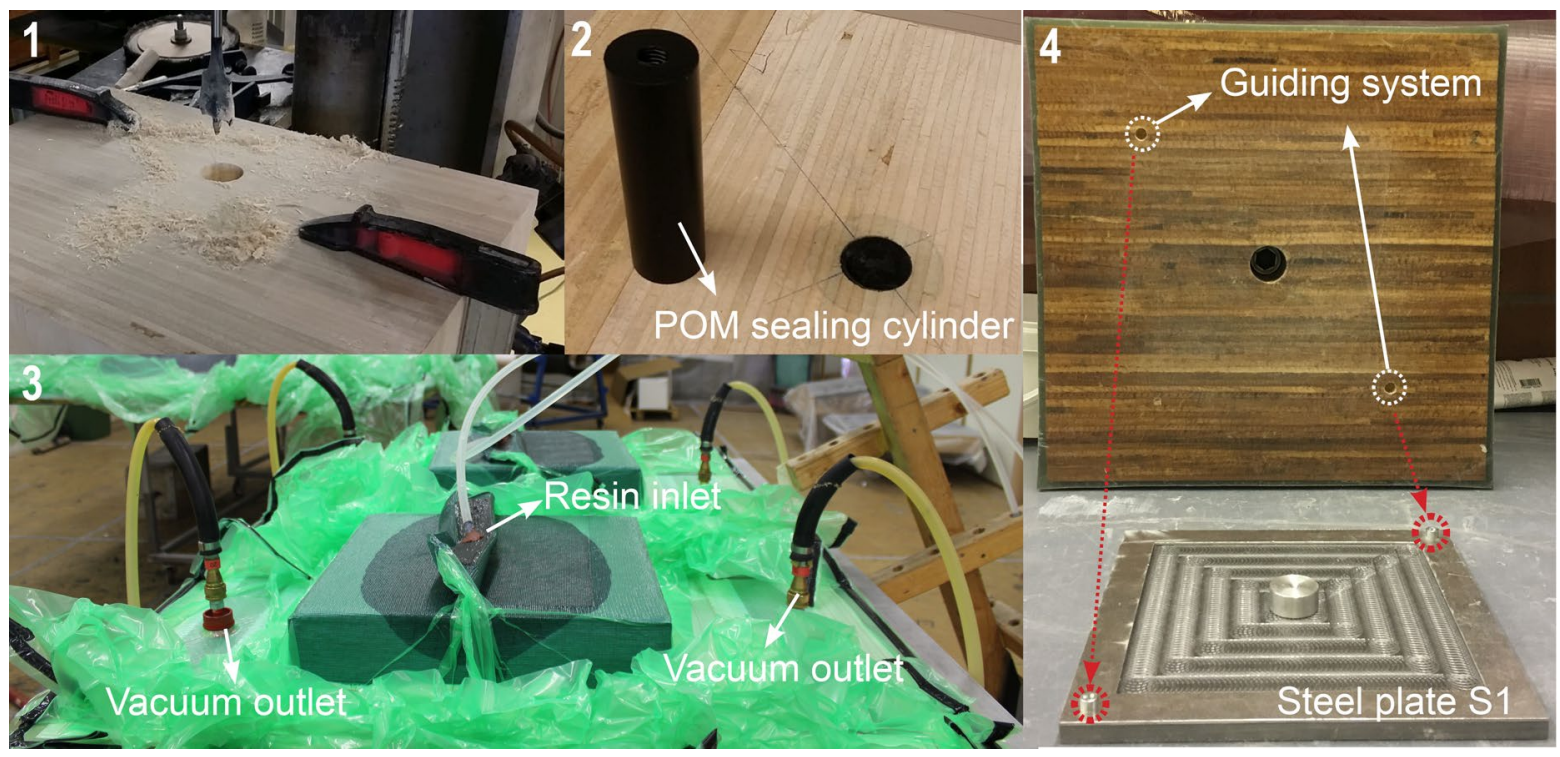

Fig. 3. Fabrication sequence 


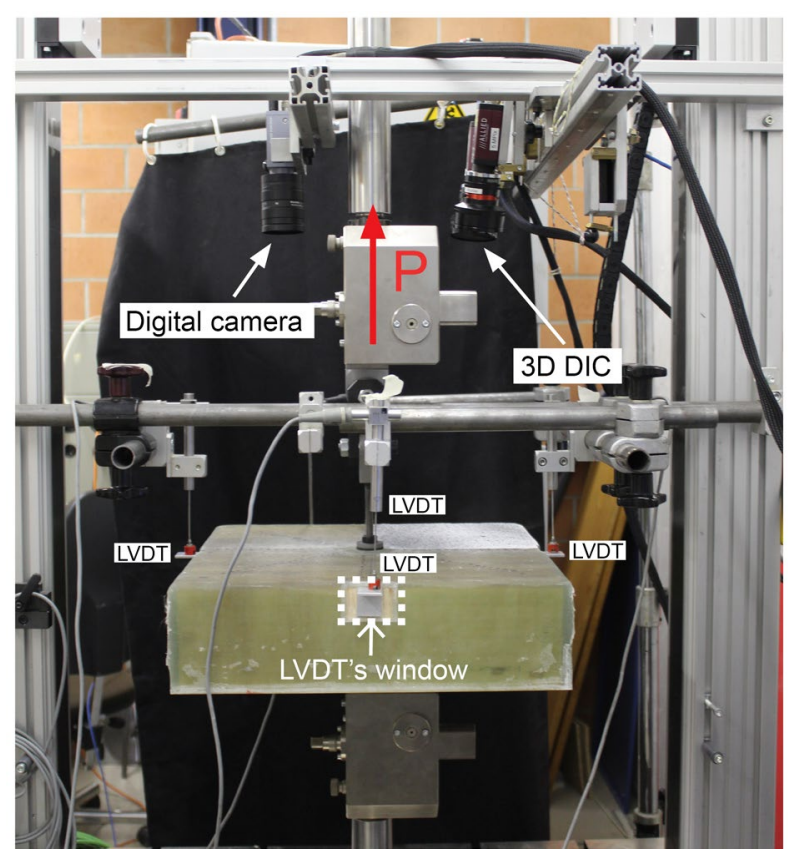

Fig. 4. Experimental set-up

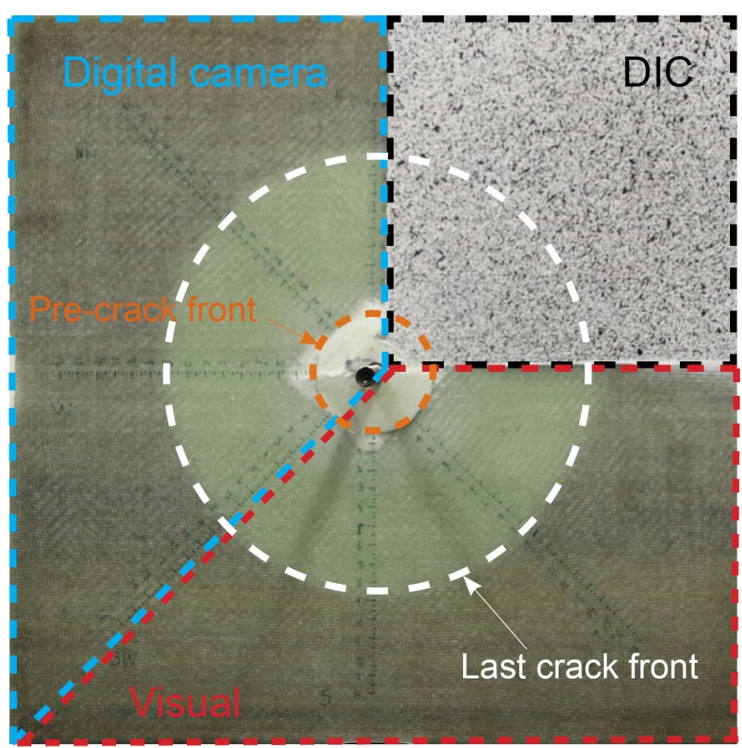

Fig. 5. Crack monitoring schema (common to all panels) and crack propagation pattern of sandwich panel SPA.1 


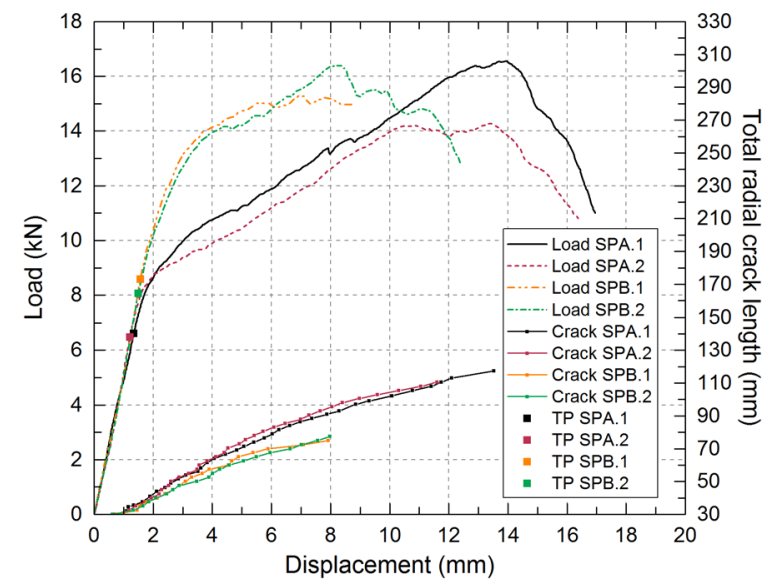

Fig. 6. Load and total radial crack lengths vs opening displacement curves

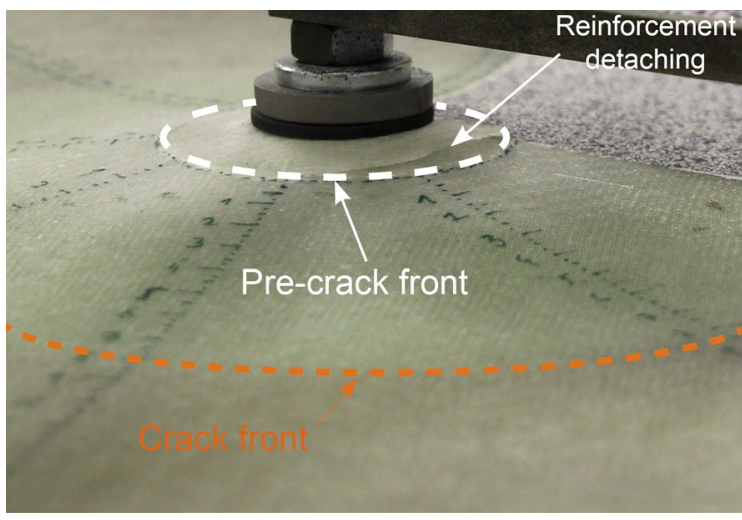

Fig. 7. Detail of loading region in SPA.1 after $75 \mathrm{~mm}$ of radial propagation (i.e. $105 \mathrm{~mm}$ of total radial crack length)

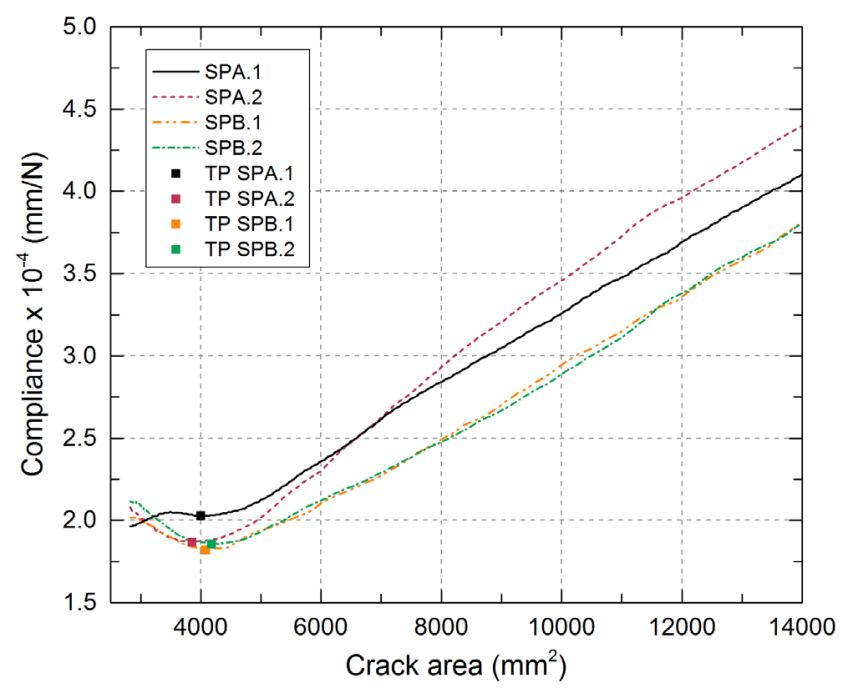

Fig. 8. Compliance vs crack area curves 

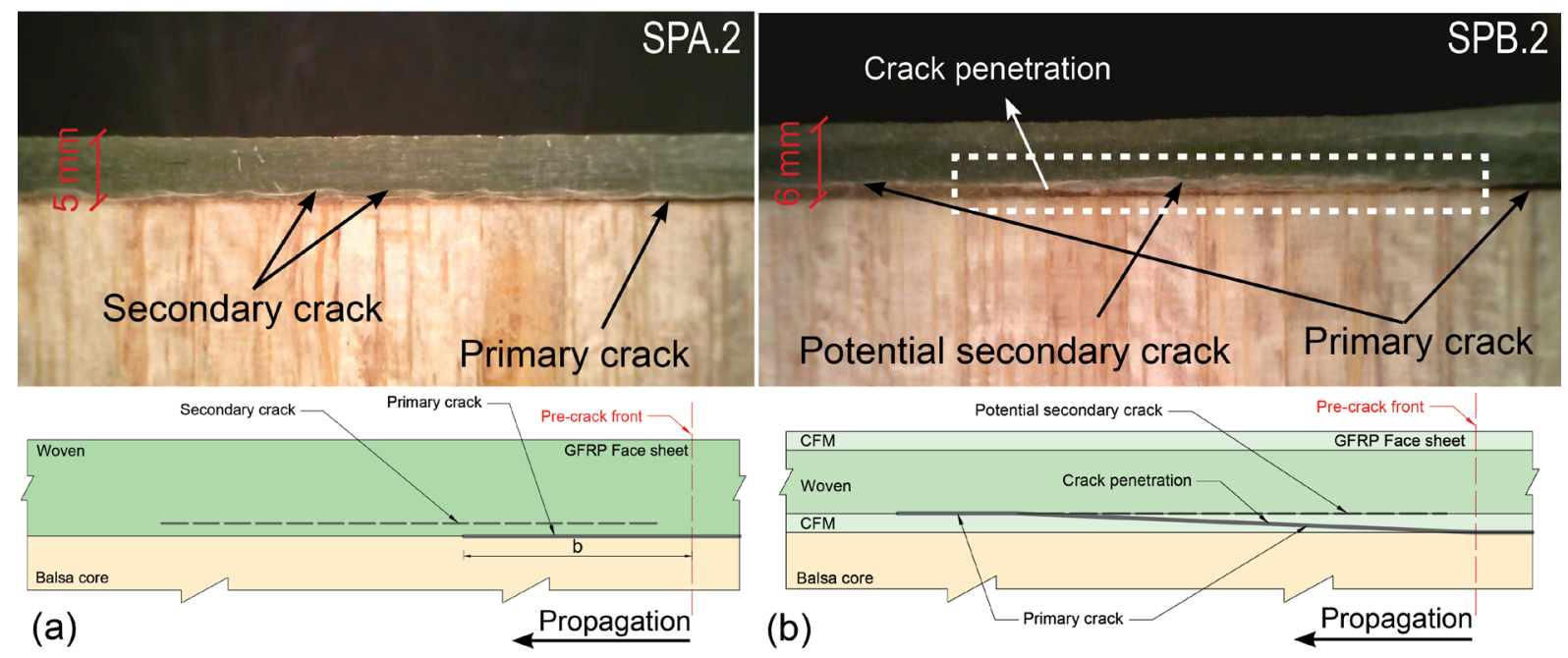

(a)

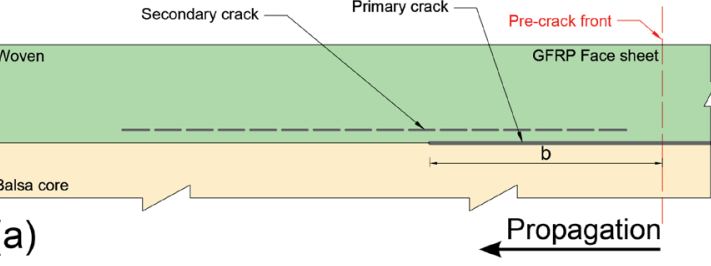

(b)

Propagation

Fig. 9. Crack interfaces of (a) sandwich panel SPA.2 and (b) sandwich panel SPB.2
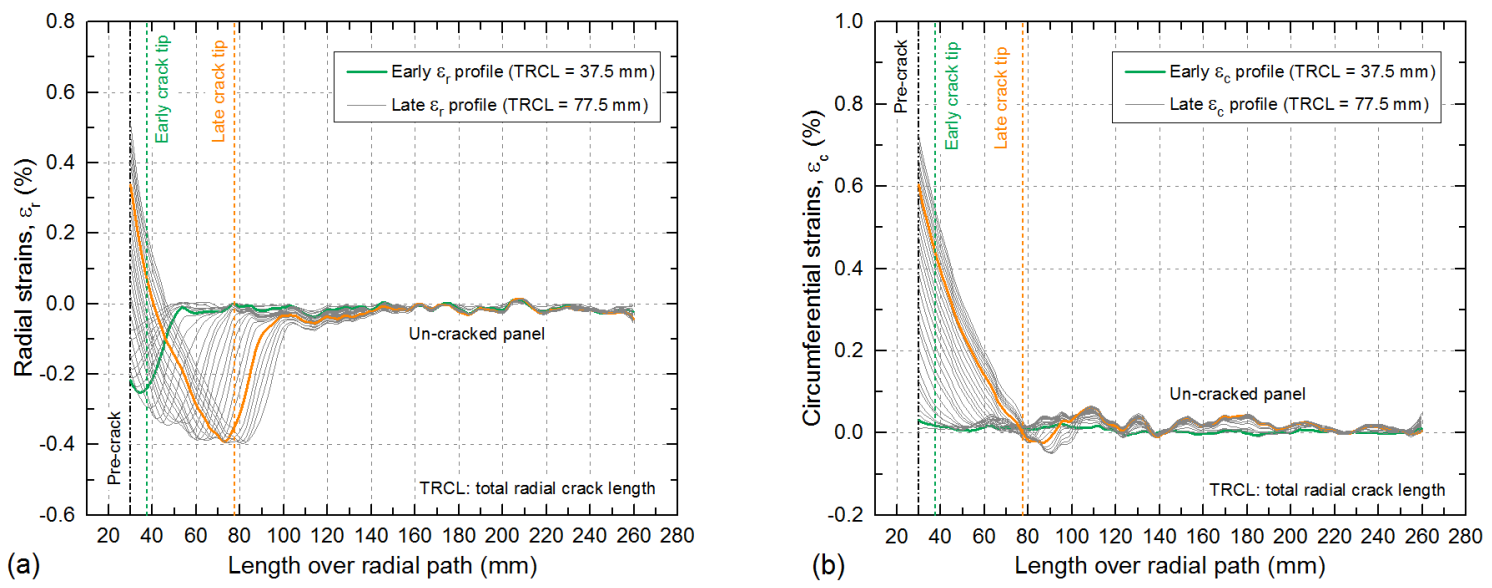

Fig. 10. Face sheet top surface in-plane strain distributions extracted from DIC; (a) in radial direction and (b) in circumferential direction for SPA.2
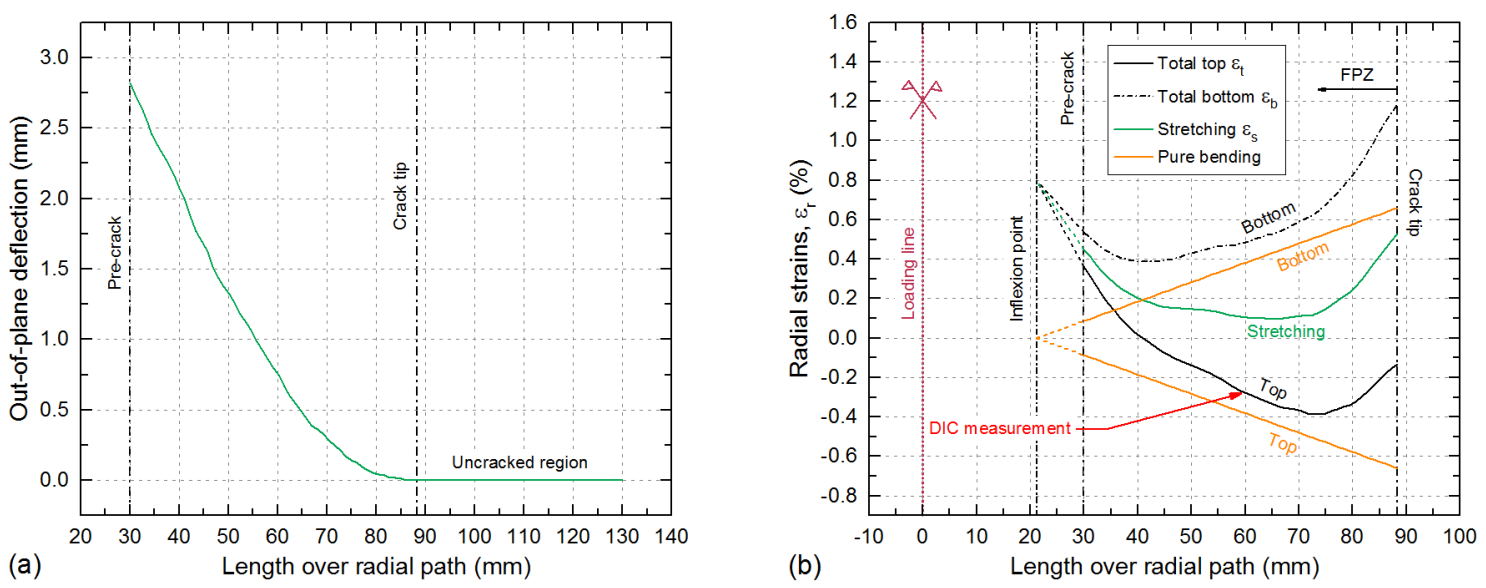

Fig. 11. Results obtained from face sheet top surface of panel SPA.2 at total radial crack length of $88 \mathrm{~mm}$; (a) out-of-plane DIC radial deflection profile; (b) radial strain profiles extracted and derived from DIC experimental results 


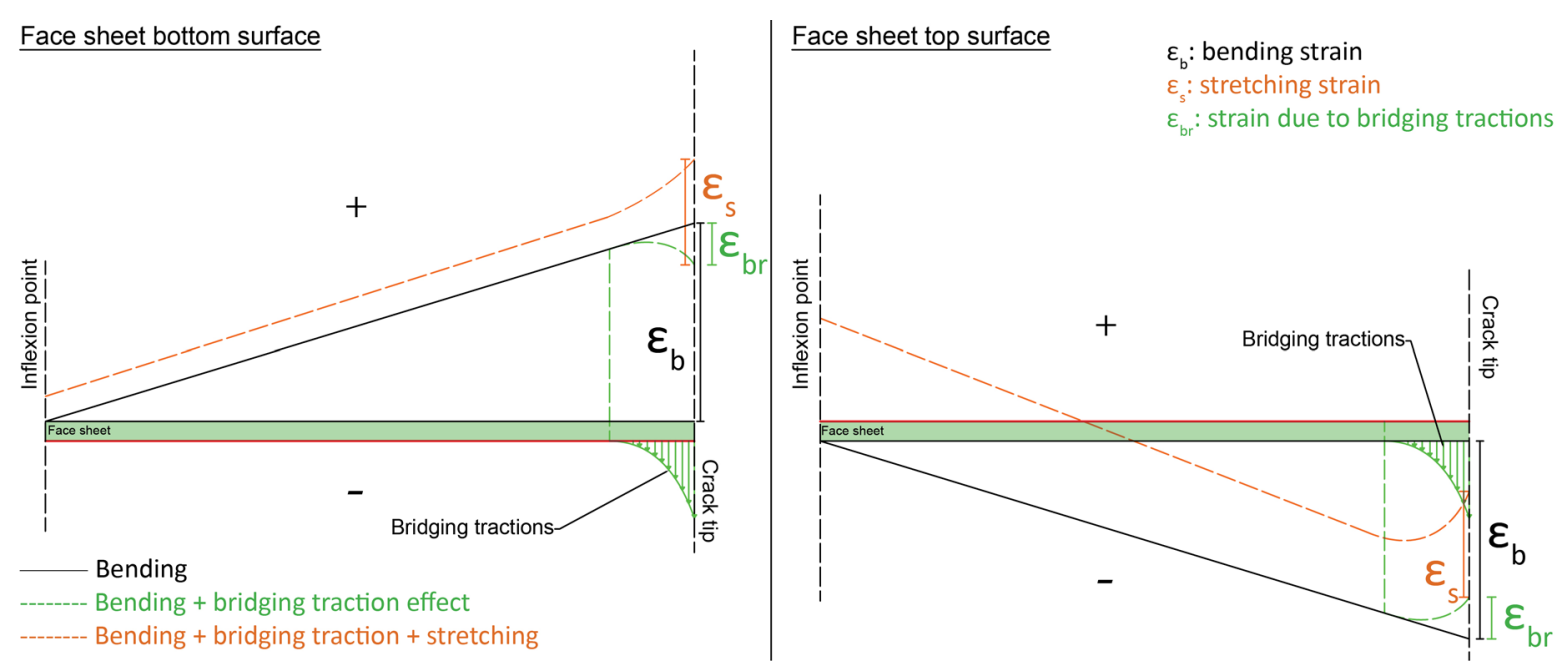

Fig. 12. Qualitative sketch of effect of stretching and fiber-bridging traction on radial strain profile of face sheet (not to scale)

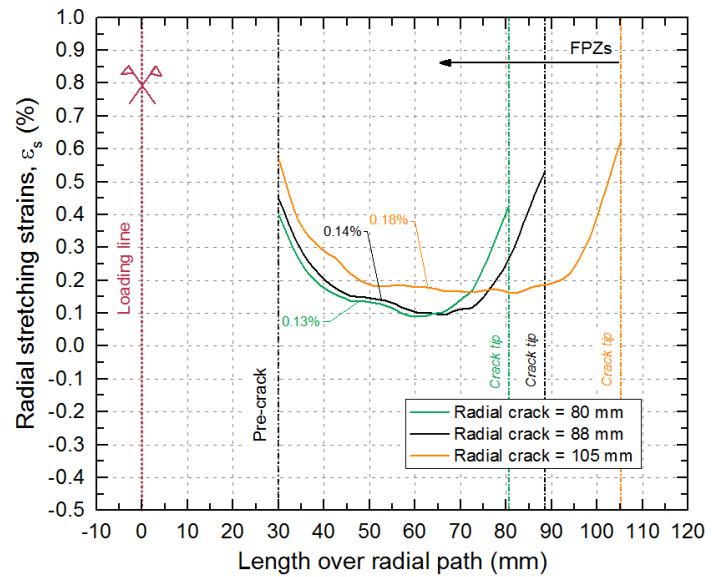

Fig. 13. Comparison of calculated radial stretching strains of SPA.2 at total radial crack lengths of 80,88 and $105 \mathrm{~mm}$; values at $60 \%$ of total crack length 


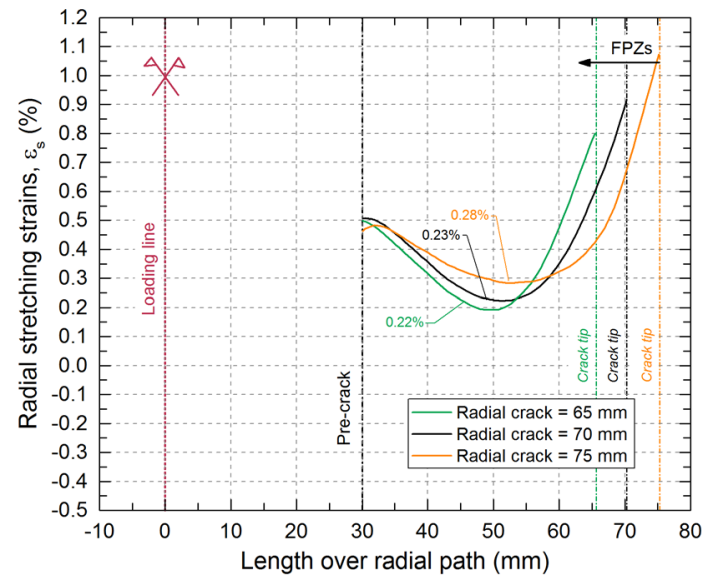

Fig. 14. Comparison of calculated radial stretching strains of SPB.2 at total radial crack lengths of 65,70 and $75 \mathrm{~mm}$; values at $70 \%$ of total crack length

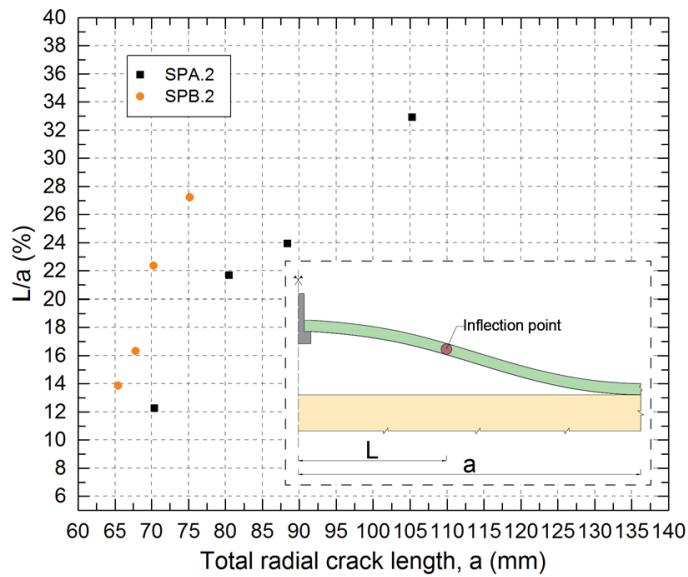

Fig. 15. Evolution of inflection point with crack propagation for (a) SPA.2 and (b) SPB.2 